\title{
Assessment of Mouse Oocytes Ultrastructure Following Vitrification Before and After in vitro Maturation
}

\author{
Evaluación de la Ultraestructura de los Ovocitos de Ratón Después \\ de la Vitrificación Antes y Después de la Maduración in vitro
}

Maryam Izadi' ${ }^{1}$, Seyed Hassan Eftekhar Vaghefi ${ }^{1}$; Hakimeh Akbari ${ }^{1}$; Majid Asadi Shekari² \& Tahmineh Mokhtari ${ }^{3,4}$

IZADI, M.; EFTEKHAR, V. S. H.; AKBARI, H.; ASADI, S. M. \& MOKHTARI, T. Assessment of mouse oocytes ultrastructure following vitrification before and after in vitro maturation. Int. J. Morphol., 36(1):180-188, 2018.

SUMMARY: Vitrification is a physical process in which the concentrated cryoprotectant solution after exposure to extreme cold without ice crystal formation in living cells to be converted glassing state. In this study, maturation rate and ultrastructure of mouse oocytes followed by vitrification before or after in-virto maturation (IVM) were evaluated. A total of 373 germinal vesicle oocytes were obtained from ovaries and divided into three fresh IVM, IVM vitrified, vitrified IVM groups. Ten metaphase II oocytes were obtained from uterine tubes and considered as the control group. Oocytes in vitrified groups were vitrified by Cryotop using vitrification medium and kept in liquid nitrogen. The maturation media was a-MEM supplemented with rFSH + hCG. After 24-48 h of incubation, the oocytes were investigated for nuclear maturation and ultrastructural changes using transmission electron microscopy (TEM). The oocyte maturation rate in vIVM group was significantly lower than IVMv group, when the two groups were compared with vIVM had the highest maturity. The evaluation ultrastructure of the four groups showed that the number of cortical granules, microvilli and mitochondria-SER aggregates in vIVM group were lowest and the highest amongst the number of vacuoles. Zona pellucida was darker than the control group in two freeze groups vIVM and IVMv. Most similar groups to the control group were group vIVM, Group IVMv and ultimately vIVM group, respectively. According to the results, IVM procedure is more efficient when it is performed before oocyte vitrification.

KEY WORDS: Vitrification; Fertility preservation; Cryopreservation; In Vitro Maturation; Ultrastructure.

\section{INTRODUCTION}

It has been estimated that 9-14\% of infertile couples faced with the problem of infertility in the developed countries and infertility is considered as a public health issue (Walschaerts et al., 2012). In recent years, fertility preservation in infertile women has been introduced as an important component assisted reproductive technology (Tucker et al., 1998). Natural declines to fertility capability intensify following gonadotoxic treatments for cancer and other non-cancerous diseases (Elizur et al., 2008). Cryopreservation of oocyte can be helpful in fertility preservation and development of assisted reproductive technology (Chen, 1986; van Uem et al., 1987). This technique may be an important alternative for fertility preservation in women that need to postpone the use of their gametes with various reasons such as having unsuccessful IVF, ovarian hyper stimulation syndrome (OHSS), or inability to obtain sperm on fertilization day, as well as for women who have to do chemotherapy or radiation therapy for cancer (Gardner et al., 2007; Gook \& Edgar, 2007).

Oocyte cryopreservation is a reasonable alternative to moral and religious problems that exist for cryopreservation of embryos, and undoubtedly helped to for reproductive technology. However, unlike the embryo, mature oocyte freezing is difficult, due to the differences in oocyte and embryo permeability membrane, the presence of the mitotic spindle forms, and eventually physiological conditions for oocyte (Paynter, 2000). In recent years, studies have shown that vitrification reduces cryodamage compared to other cryopreservation technologies (Cobo et al., 2008; Homburg et al., 2009). Vitrification is a physical process involving rapid freezing with a low volume of a concentrated

\footnotetext{
${ }^{1}$ Department of Anatomical Sciences, Afzalipour School of Medicine, Kerman University of Medical Sciences, Kerman, Iran.

${ }^{2}$ Kerman Neuroscience Research Center (KNRC), Kerman University of Medical Sciences, Kerman, Iran.

${ }^{3}$ Department of Anatomy, School of Medicine, Semnan University of Medical Sciences, Semnan, Iran.

${ }^{4}$ Research Center of Nervous System Stem Cells, Department of Anatomy, School of Medicine, Semnan University of Medical Sciences, Semnan, Iran.
} 
solution cryoprotectant (antifreeze) without forming ice crystals (Campos-Chillòn et al., 2009). Vitrification leads to a significant decrease in the rate of oocyte degeneration (Flaws et al., 2001).

One of the main problems of mature oocytes (MII) freezing is meiotic spindles sensitivity to low temperatures and cryoprotectants. This problem can be solved by immature oocyte cryopreservation at GV stage in which chromosomes remain inside the nuclear membrane and the mitotic spindles have not formed (Bonduelle et al., 1999). Cryopreservation of immature oocyte may be useful during assisted reproductive techniques (ART) in combination with in vitro maturation (IVM) (De Vos et al., 1999; Ben-Ami et al., 2011; Hreinsson \& Fridström, 2004). IVM performance before freezing may lead to more sensitivity of oocytes, due to freezing associated damages and additional stress on the oocyte. So, it is more logical to perform IVM after cryopreservation of immature oocyte (Wu et al., 2001; Cao et al., 2009). Up to now, information on freezing immature oocyte is limited, due to poor results and this can be either due to direct damage of cryopreservation process on oocyte or the lack of compatibility with guidelines of in vitro maturation (Toth et al., 1994). Recently, it has been shown that there is no difference between the survival rate of frozen oocyte and vitrification method in GV step and MII. However, maturation ability of vitrified immature oocytes will be reduced (Cao et al.).

Vitrification method is associated with ultrastructural alterations in specific areas of oocyte which is probably related to the decrease of vitrified oocytes competence for Maturity (Wu et al., 2006). The aim of this study was to compare the effect of vitrification on the ultrastructure of mice immature oocyte before and after in vitro maturation.

\section{MATERIAL AND METHOD}

Animals. In this study, 60 Adult female (6-8 weeks old) NMRI mice were kept under a cycle of $12 \mathrm{~h}$ light: $12 \mathrm{~h}$ dark at $22-24{ }^{\circ} \mathrm{C}$ and $40-50 \%$ humidity and were fed with food and water available (Nazmara et al., 2014).

\section{Preparation of GV and MII oocytes.}

Oocytes of GV stage: Adult female mice ovaries were superovulated by intraperitoneal injection (IP) of 10 IU pregnant mare serum gonadotrophin (PMSG, Folligon; Intervet, Australia). To obtain GV oocytes, females were sacrificed by cervical dislocation $48 \mathrm{~h}$ after PMSG injection and dissected ovaries were placed in global total (Life Glo- bal, USA) (Nazmara et al.) or a-MEM medium (Gibco) (Oryan Abkenar et al., 2014). Antral follicles were punctured using needles to release the GV oocytes. Cumulus cells were mechanically removed.

Oocyte of MII stage oocyte: To obtain MII oocytes, adult female mice ovaries were superovulated by IP injection of 10 IU PMSG followed with another injection of 10 IU human chorionic gonadotrophin (hCG, Sereno, Switzerland) $48 \mathrm{~h}$ later. The mice were killed by cervical dislocation 12-16 h after hCG injection and their uterine tubes were removed. The Cumulus-Oocyte-Complex (COC) was released with a needle from the ampullary region of each uterine tube then they were exposed to $0.01 \%$ hyaluronidase for $1 \mathrm{~min}$ to allow cumulus cells to separate from the oocytes. Denuded MII oocytes were washed several times in global total or aMEM medium. The collected GV and MII oocytes were considered as vitrified and nonvitrified ones. GV stage oocytes were divided into three groups and two groups were vitrified (Nazmara et al.).

Vitrification and warming. Oocytes were vitrified via cryotop method. The equilibration solution (ES) including $7.5 \%$ (v/v) dimethyl sulphoxide (DMSO) and $7.5 \%$ ethylene glycol (EG) in Ham's F10 containing $20 \%$ human serum albumin (HSA) was used. The vitrification solution (VS) was consisted by $15 \%$ (v/v), DMSO, $15 \%$ EG and $0.5 \mathrm{M}$ sucrose in Ham's F10 containing $20 \%$ HSA. Three/five oocytes were equilibrated in ES for $10 \mathrm{~min}$ and then transferred to VS for 45-60 s. Finally, the oocytes were loaded on to the strip end of cryotop with a small volume of VS $(<0.1 \mathrm{ml})$ and immersed in liquid nitrogen $(\mathrm{LN})$ at least for $24 \mathrm{~h}$.

For warming, the cap of strip was removed and then the strip of cryotop was directly placed into $1 \mathrm{M}$ sucrose at $37^{\circ} \mathrm{C}$ for $1 \mathrm{~min}$. Next, it was consecutively transferred to $0.5 \mathrm{M}$ sucrose for $3 \mathrm{~min}$ and $0.25 \mathrm{M}$ sucrose for $3 \mathrm{~min}$ and subsequently washed in Ham's F10. After this process, GV oocytes were placed into in vitro maturation media and MII in culture media, respectively.

In vitro maturation (IVM). Oocytes were cultured in 20 $\mathrm{ml}$ droplet of global or media supplemented daily with 75 $\mathrm{mIU} / \mathrm{ml} \mathrm{rFSH}$ (Sereno, Switzerland) and $10 \mathrm{IU} / \mathrm{ml} \mathrm{hCG}$ under mineral oil at $37^{\circ} \mathrm{C}$ in $5 \% \mathrm{CO}_{2}$ in air for $24 \mathrm{~h}$. The extrusion of the first polar, the appearance of the first Plarbady was the maturity criterion of GV stage oocytes (Nazmara et al.).

Transmission electron microscopy (TEM). Ultrastructure architecture of oocytes was evaluated using TEM. In this way, 10 isolated oocytes from each group were selected. At 
least five oocytes from each group were fixed in $2.5 \%$ glutaraldehyde in $0.1 \mathrm{M}$ phosphate buffer (pH: 7.4) for $1 \mathrm{~h}$ at $4{ }^{\circ} \mathrm{C}$, and washed in the same buffer for 10 min. Oocytes were then post-fixed in $1 \%$ osmium tetroxide, washed in phosphate buffer and dehydrated in ascending concentrations of ethanol followed by propylene oxide. The oocytes were embedded in Araldite resin (Merck, Germany), sectioned at a thickness of $50 \mathrm{~nm}$, stained with alcoholic uranyl acetate (7 $\mathrm{min})$ and aqueous lead citrate $(13 \mathrm{~min})$ and investigated with a TEM-900 electron microscope (Valojerdi \& Salehnia, 2005).

Statistical analysis. Statistical analysis was performed using the SPSS software (version 20). Differences in oocyte maturational stages and their morphology between the groups were calculated and compared using Chi-square test. P-value $<0.05$ was considered statistically significant.

\section{RESULTS}

In this study, we used 243 immature GV oocytes and 10 MII oocyte obtained from 60 adult female MNRI mice. Oocytes were divided into four groups. The first group consisted of 10 mature oocytes that were used as control group. The second group included $10 \mathrm{GV}$ oocytes which after retrieval were directly undergone the in vitro maturation. The third group included $113 \mathrm{GV}$ oocytes that had initially undergone IVM oocytes and then were vitrified thawed. The fourth group included $120 \mathrm{GV}$ oocytes that were first vitrified and then used for IVM. Given that this study consisted of two parts; IVM and ultrastructure study and the results of each part were examined separately.

In vitro maturation (IVM) effects. In this part oocytes maturation results were compared in the third (IVMv) and fourth (vIVM) groups respectively in terms of the cytoplasm, zona pellucida and PVS. As Table I and Figure 1 show, maturation rate (MR) of third group was higher than the fourth group (67.2\% vs $43.2 \%)$. Percent of MII oocytes with cytoplasm, the zona pellucida and normal PVS in third group was significantly higher than the fourth group (49.6 $\%$ vs $34.2 \%$ ) (Fig. 1). The percentage of MII oocytes with normal cytoplasm and zona pellucida and abnormal PVS was $0.0 \%$ and $3.3 \%$ in the third and fourth groups, respectively. Also, the percentage of MII oocytes with abnormal cytoplasm and normal zona pellucida and PVS was in the third and fourth group was (8.8\% vs $5.8 \%)$, respectively, the percentage of MII oocytes with abnormal cytoplasm and PVS and normal zona pellucida was $(8.8 \%$ vs $0.0 \%$ ) in the third and fourth groups respectively (Table I). The other remaining oocytes arrested at GV and MI stage that the percentage of GV arrest in the fourth group was higher than the third group and the percentage of MI arrest in the third group higher than the fourth group. Comparing the effects of vitrification on the maturation of oocytes in the vIVM and IVMv groups and their appearance indicated that vitrification caused further reduction in MR of GV oocyte and normal MII oocytes in vIVM group in comparison with IVMv group. Therefore, it was concluded maturation of oocytes before vitrification may have better results.

\section{Ultrastructural architecture with transmission electron microscopy (TEM).}

In this section the effect of vitrification on the ultrastructure of oocytes in third (IVMv) and fourth (vIVM) groups were evaluated and compared with the second (vIVM) and control groups.

Assessment of MII oocytes ultrastructure (first group). Membrane structure was continuous and coherent and the zona pellucida (ZP) of control MII oocytes composed of electron dense fibrillar material and completely surrounds the oocyte. The perivitelline was observed between zoona pellucida and oolemma (Fig. 2a). Continuous oolemma had numerous microvilli uniformly drawn to PVC (Fig. 2a). Microvilli in this group was longer and numerous than other groups with the lower number of vacuoles. Round cortical granules with an electron dense and round appearance arranged as a layer beneath the plasma membrane with most density between groups (Fig. 3a). Mitochondria are spherical or oval shape mitochondria were scattered both individually and in groups all over the cytoplasm (Figs. 2a, 4a). Additionally, it had highest aggregates of mitochondria smooth endoplasmic reticulum (M-SER aggregates) (Fig. $4 a)$. The majority of cytoplasmic organelles were related to smooth and rough endoplasmic reticulum which indicated the cytoplasm activities (Fig 5a). Most similar groups to the control group were related to the second group (IVM), Group III (IVMv), and the fourth group (vIVM), respectively.

\section{Assessment of immature GV oocytes ultrastructure after} IVM (second group). Membrane structure was continuous and coherent and the zona pellucida (ZP) was clear and electron dense and completely surrounded the oocyte. The perivitelline was observed between zona pellucida and oolemma (Fig. 2b). Continuous oolemma had numerous microvilli uniformly drawn to PVC (Fig. 2b). Cortical granules had an electron dense and round appearance which arranged to form a layer beneath the plasma membrane. Mitochondria were spherical or oval shape. Mitochondria were scattered both individually and as groups in the cytoplasm (Fig. 2b, 4b). The majority of cytoplasmic 


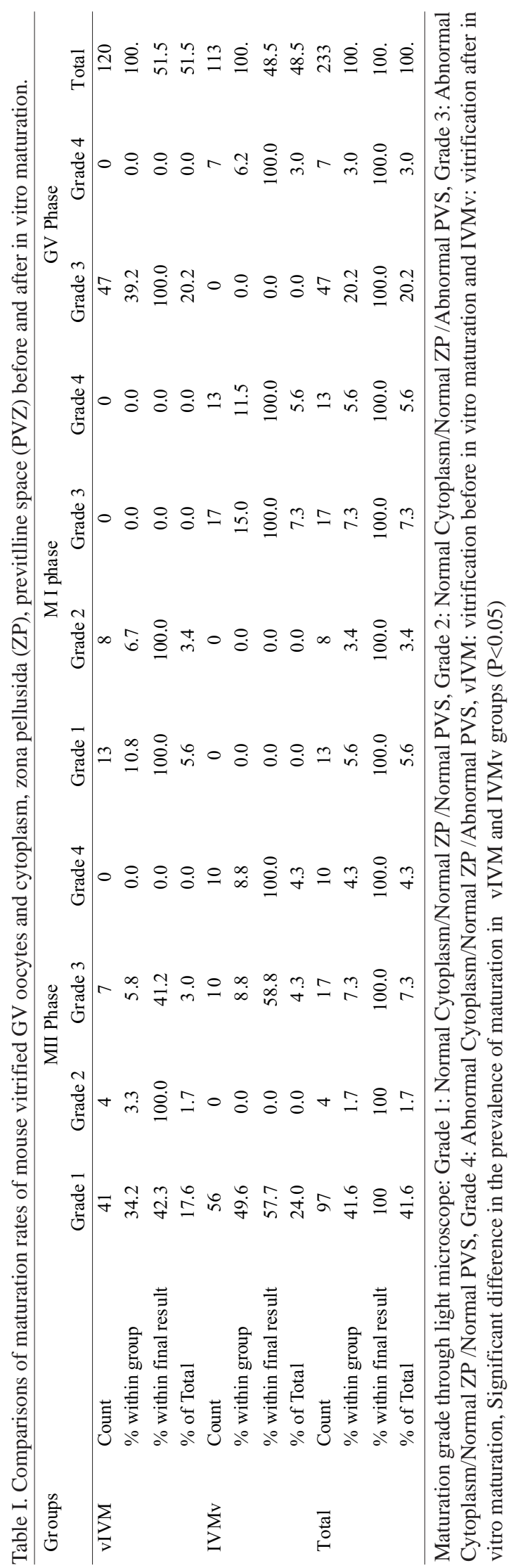

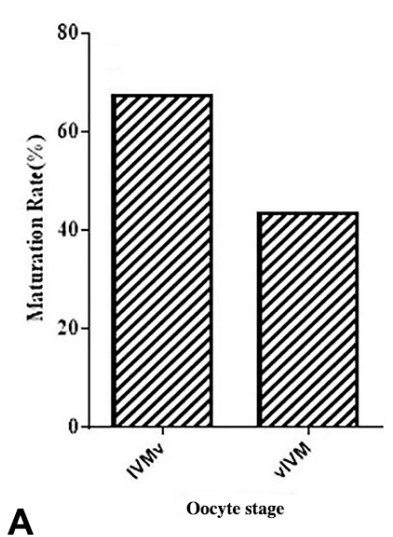

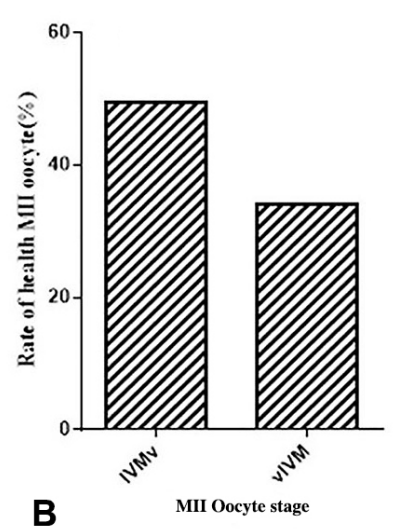

Fig. 1. Evaluation of in-vitro maturation rate following vitrification before and after in vitro maturation. (a) In-vitro maturation rates of immature mouse oocytes with or without vitrification for IVM. A total of 233 immature oocytes (113 immature oocytes without vitrification and 120 immature oocytes with vitrification) were cultured in vitro for maturation. There were significant differences $(\mathrm{P}<0.05)$ between those two groups (b) Rate of MII oocyte in IVMv and vIVM groups. Significant differences $(\mathrm{P}<0.05)$ between vIVM and IVMv groups.
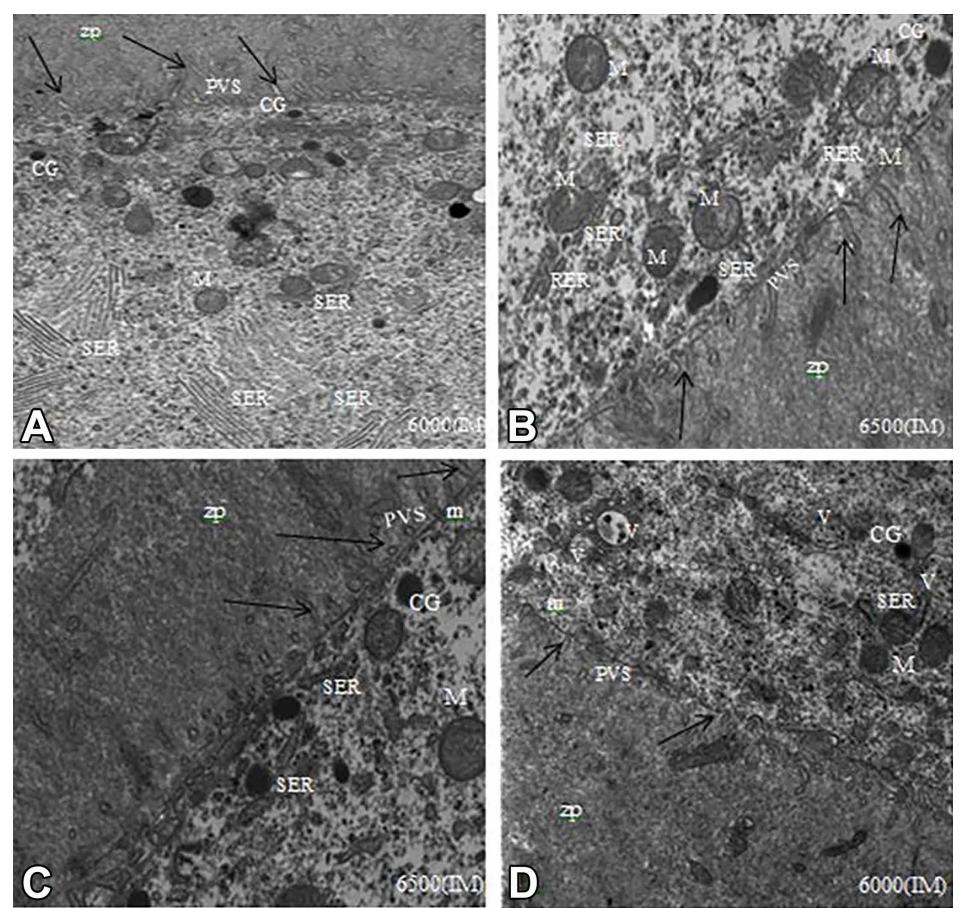

Fig. 2. Ultrastructure of control oocyte (a), GV stage oocyte after IVM (b), vitrified-thawed GV oocyte After IVM (c), vitrified-Thawed GV oocyte before IVM (d). zp = zona pellusida, $\mathrm{PVS}=$ Pervitelline space, $\mathrm{m}=$ membrain, $\mathrm{CG}=$ cortical Granules, $\mathrm{V}=$ vacoule, $\mathrm{SER}=$ smooth endoplasmic reticulum, RER = rouph endoplasmic reticulum, $\mathrm{M}=$ Mitochondria 

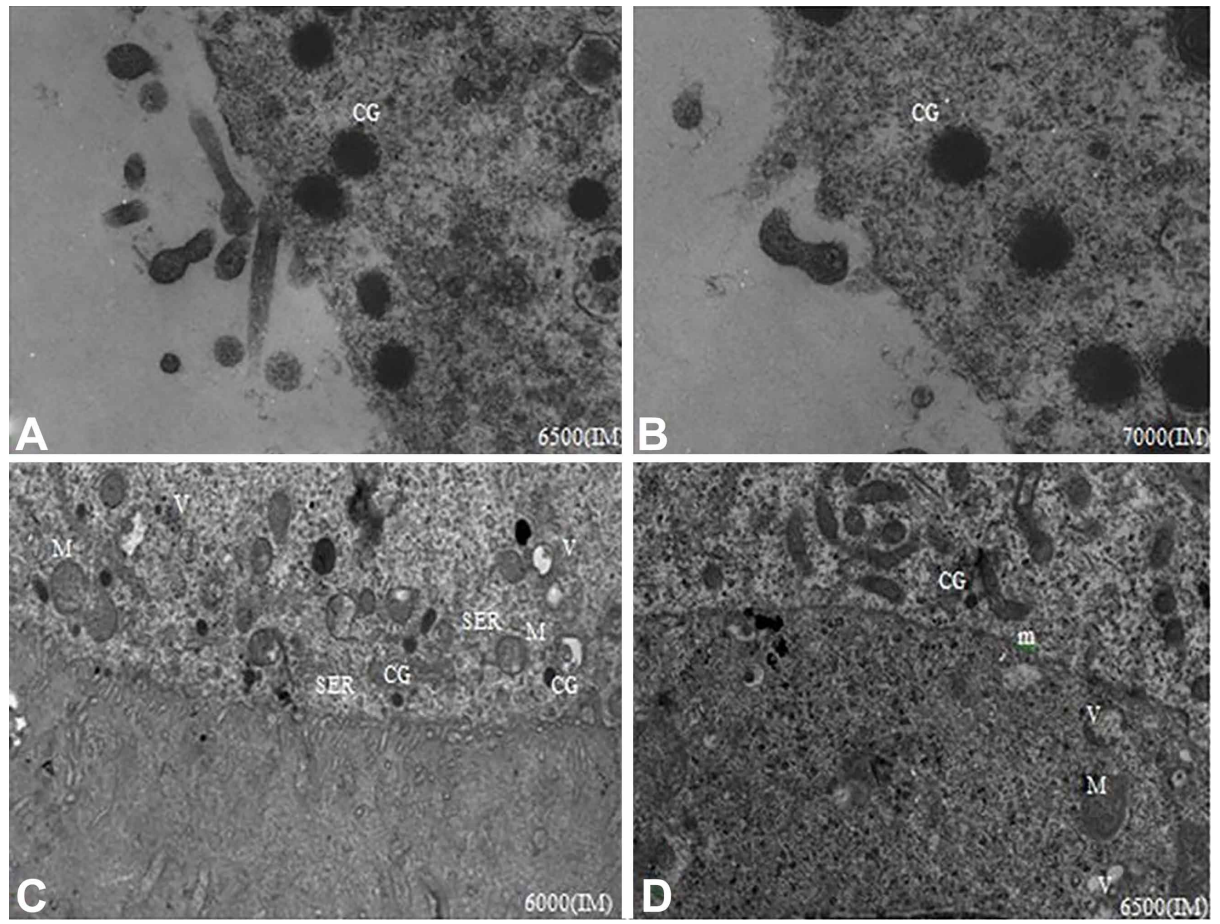

Fig. 3.The cortical granules of control oocyte (a), GV stage oocyte after IVM(b), vitrified-thawed GV oocyte after IVM(c), Vitrified-thawed GV oocyte before IVM(d), CG = cortical granules, M $=$ mitochondria, $\mathrm{SER}=$ smooth endoplasmic reticulum, $\mathrm{m}=$ membrain, $\mathrm{V}=$ vacuole
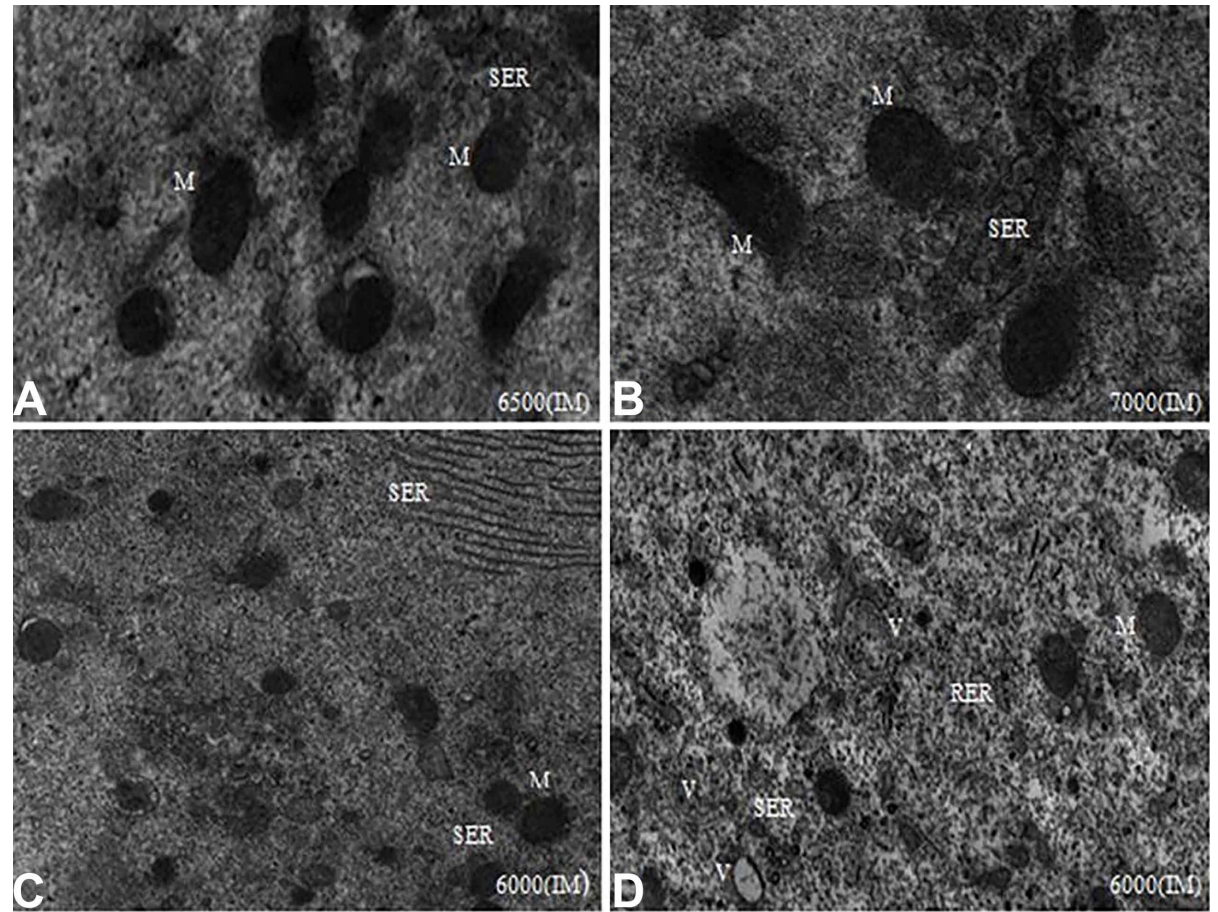

Fig. 4. Mitochondria and smooth endoplasmic reticulum aggregates of control oocyte (a), GV oocyte after IVM(b), vitrified - thawed GV oocyte after IVM (c), vitrified-thawed GV oocyte before IVM (d), M = mitochondria, SER = smooth endoplasmic reticulum, $\mathrm{V}=$ vacuole. organelles were related to smooth and rough endoplasmic reticulum represented the cytoplasm activities (Fig. 5b). Compared with control group, less cortical granules (Fig. 2b) and reducing M-SER aggregates (Figs. 2b, 4b) was observed in this group.

\section{Assessment of} immature GV oocytes ultrastructure after IVM and then vitrification (third group). Membrane structure was continuous and coherent and the zona pellucida (ZP) completely had surrounded the oocyte and was darker because of cortical granules sedimentation. The perivitelline was observed between zona pellucida and oolemma (Fig. 2c). The cortical granules in this group were more than fourth group. Mitochondria were spherical or oval shape. Both as a group and individually mitochondria were scattered in the cytoplasm. Mitochondria in this group were bigger and bulkier than fourth group (Figs. 2c, 3c, 4c). The majority of cytoplasmic organelles were related to smooth and rough endoplasmic reticulum activities which represented the cytoplasm activities (Fig. 5c). Compared with control group, less cortical granules (Fig. 3c) and microvilli, shorter microvilli (Fig. 2c), more vacuoles (Fig. $3 c$ ) and reduced M-SER aggregates (Figs. 3c, 4c, 5c) were observed in this group.

\section{Assessment}

of

immature GV oocytes ultrastructure after vitrification and then IVM (fourth group). Membrane structure was continuous and coherent and 

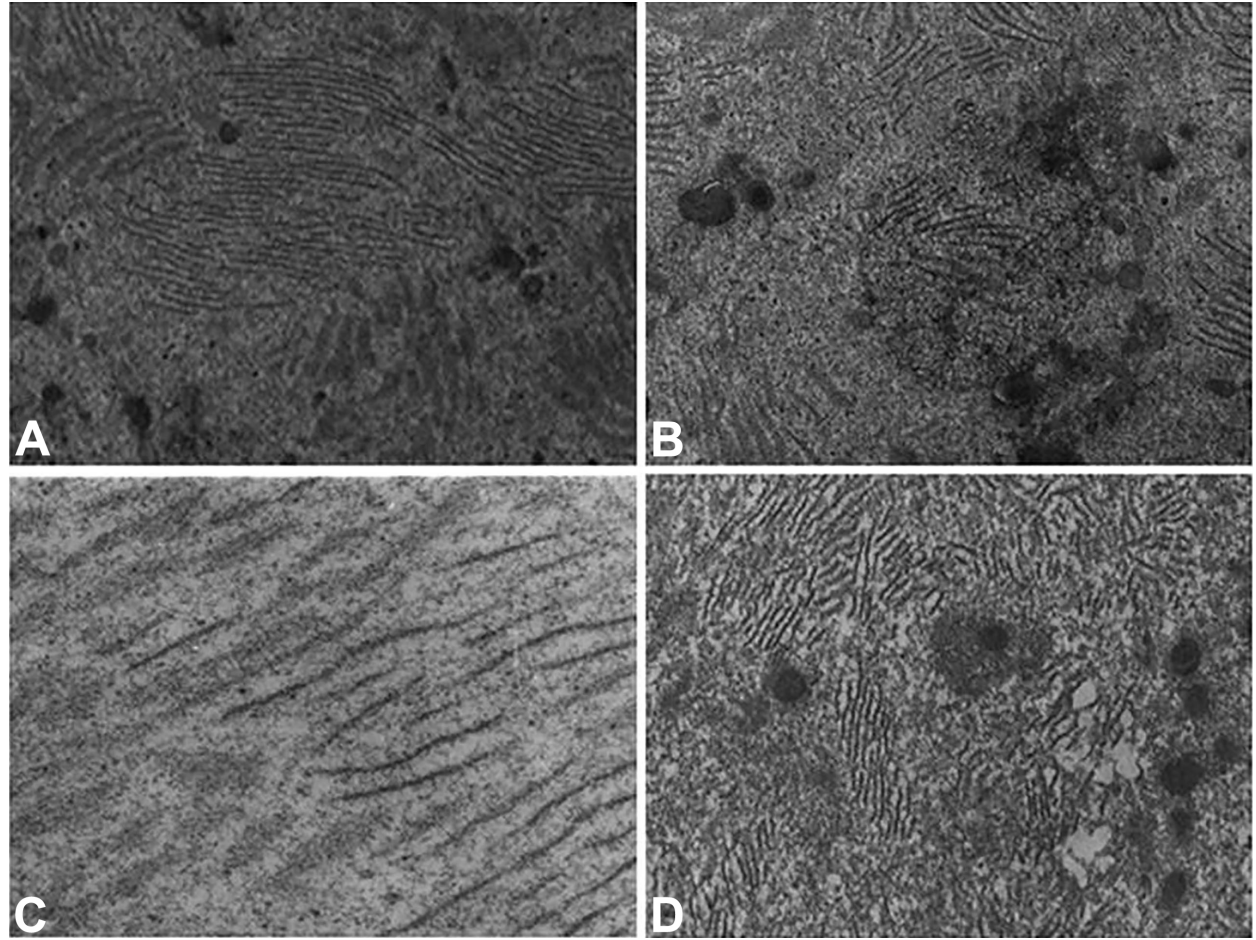

Fig. 5.Aggregation of smooth and rouph endoplasmic reticulum of control oocyte(a), GV oocyte after IVM, vitrified-thawed GV oocyte after IVM(C), vitrified-thawed GV oocyte before IVM(d).

the zona pellucida (ZP) was darker and thicker because of cortical granules sedimentation and completely had surrounded the oocyte. The perivitelline was observed between zona pellucida and oolemma (Fig. 2d). Cortical granules were fewer in this group compared with the other groups and had more vacuole. Mitochondria were spherical or oval shape. Mitochondria were scattered both as groups and individually in the cytoplasm. Mitochondria in this group were smaller than third group (Figs. 2d, 3d, 4d). The majority of cytoplasmic organelles were related to smooth and rough endoplasmic reticulum activities demonstrated the cytoplasm activities (Fig. 5d). Endoplasmic reticulum density was lower than other groups. Compared with control group, darker zona pellucida, less cortical granules and microvilli, shorter microvilli (Figs. 2d, 3d), more vacuoles (Figs. 2d, 3d, 4d) and Reducing M-SER aggregates (5d) were observed in this group.

\section{DISCUSSION}

In vitrification, the oocytes may be prone to damage by a variety of factors, including the toxicity of cryoprotectants, cold shock, and incomplete vitrification (allowing some ice crystal formation) which resulting osmotic stress (Yoon et al., 2003). Essentially, the maturation stage of vitrified oocytes may impact the efficiency of the IVM process (Fasano et al., 2010). Cryopreservation of oocytes at metaphase I and II may frequently be accompanied by irreversible damage to the spindle which can affect chromosomal organization and alignment (Van Blerkom, 1989). Theoretically, due to their microstructure, immature germinal vesicle (GV) stage oocytes should be more resistant to the damage caused by cooling and circumvent and the risk of polyploidy and aneuploidies was lower since the chromatins are diffused and surrounded by a nuclear membrane (Cooper et al., 1998).
The disadvantage of cryopreservation of immature oocytes is this that in vitro maturation (IVM) should be required after thawing (Wu $e t$ $a l$. .). Although, survival rate of oocyte seems to be improved, maturation, fertilization and poor embryonic development are the main problems associated with immature oocyte cryopreservation (Toth et al.). In a study by Huang $e t$ al., conducted on mice oocytes, the oocytes were vitrified in MII stage and obtained high survival rate and no increased incidence of aneuploidy (Huang et al., 2008).

This study aimed to evaluate the effects of vitrification on in vitro maturation and ultrastructure of immature mice $\mathrm{GV}$ oocytes before and after IVM. Based on the results obtained from morphological assessment, after in vitro maturation, rate of MII oocyte with normal appearance significantly ( $\mathrm{p}$ $<0.05)$ reduced in the fourth group (vIVM) compared to the third group (IVMv) (49.6 $\%$ vs $34.2 \%$ ). Moreover, it was demonstrated that the immature oocytes in ART cycles should be matured at first and then subjected to vitrification. Abedpour \& Rajaie (2015) evaluated the effects of vitrification on maturation, fertility and development of mice oocytes carried out by cryotop. They reported that the maturation of vitrified GV oocytes reduced compared to the control group (68 \% vs $84 \%$ ) (Abedpour \& Rajaei). In the present study, also, the 
maturation rate in fourth group (vIVM) was lower than the third group (IVMv), but the maturation rate was lower in this group probably due to time of culture and conditions of IVM.

According to the literature, several factors including media composition, hormonal or growth factor supplementations, the source of oocytes (stimulated versus unstimulated cycles) and retained cumulus cells with oocyte affect the maturation rate after IVM (Combelles et al., 2002). In addition, the beneficial impacts of cumulus cells on maturation of human oocyte have been reported (Kennedy $\&$ Donahue, 1969). The mediums using for maturation of mammalian oocytes significantly affect fertilization and embryo development rates (Fasano et al., 2012). Cao et al. showed that there is no difference between the survival rate of frozen oocyte via vitrification method in GV and MII steps. However, maturation ability of vitrified immature GV oocytes may be reduced (50.8 vs 70.4). The results of this study showed that vitrification of oocytes after IVM compared to vitrification in GV stage improve the chances of success. Their finding confirmed the results of present study (Cao et al.).

The efficiency of IVM before and after vitrification of human immature oocytes was evaluated and showed that maturation rate of vitrified oocytes after IVM (Group 1, .46 $\%)$ specifically was higher than the oocytes before IVM (Group 2, $23.8 \%$ ). Moreover, the number of fertilized MII oocyte was even higher in this group ( $40 \%$ vs $23.8 \%$ ). The results of this study showed that IVM is more efficient when it is performed before oocyte cryopreservation which this study confirm our findings (Fasano et al.).

Furthermore, maturation and developmental retardation of cryopreserved $\mathrm{GV}$ oocytes are related to critical disturbances of various cell components, such as the chromosome segregation apparatus, the intracellular $\mathrm{Ca}+$ signaling system, and the cytoskeleton (Son et al., 1996).

More evaluations were performed with TEM to evaluate the ultrastructure of oocyte in each group. According to the results, it seems that cooling speed and cryoprotectant itself are effective on the integrity of oocyte ultrastructure during freezing-thawing (Nottola et al., 2009). A study was conducted by Shahedi et al., to evaluate the effect of vitrification on ultrastructure of immature oocytes in fIVM and vIVM groups. Their results showed that normal oocytes surrounded by an intact and continuous membrane containing long and uniform microvilli (Shahedi et al., 2013). Their results about the integrity of the oocyte membrane confirmed our findings. However, the number and size of microvilli was reduced in the vIVM and IVMv groups compared to the control group in our study. But, the size of microvilli in vIVM group microvilli was similar to the control group. These results suggest that vitrification induced damages to the microfilaments. These differences in results may be due to differences in samples of studying. Other studies have also reported damages to the fibers of the cytoskeleton and microtubules resulting from vitrification (Shi et al., 2007; Nottola et al., 2014; Sprícigo et al., 2014).

In this study, we revealed that in the cortical granules of vitrified immature oocytes decreased before and after in vitro maturation. This reduction in vIVM group was lower than IVMv group. The number of granules in both groups was lower than vIVM group and in vIVM group was lower than control group and closer to the IVMv group. Nottola et al. (2014) showed that the number of cortical granules of in vitro matured oocytes was reduced compared to control group. This was similar to our results. In a human study, it has been shown that the freezing process is a leading cause of the cortical granules reduction and emergence of vacuoles in the cytoplasm of mature and immature oocytes (Ghetler et al., 2006). These findings confirm our results. Reducing in the cortical granules and their fusion with plasma membrane which is accompanied with releasing their contents into PVS after IVM has been observed in all frozen bovine oocytes (Fuku et al., 1995). In this study, we showed that zona pellucida of vitrified oocytes was electron dense and darker compared to control and vIVM groups. These results can justify reducing the cortical granules due to early exocytosis during freezing and thawing.

Ultrastructural changes observed in the zona pellucida are similar to previous studies (Nottola et al., 2009). In the current study, the numerous vacuoles were seen in the cytoplasm of vitrified oocytes which may be a sign of structural damages to the oocyte following vitrification. The emergence of vacuoles in human frozen oocytes is a nonspecific response to cooling or osmotic stress (Nottola $e t$ $a l ., 2009)$. Numerous vacuoles in the cytoplasm of human oocytes may be caused by swelling and merging of vesicles isolated from smooth endoplasmic reticulum, considered as degenerative processes. This theory was further strengthened with observing the combination of vacuoles with lysosomes and multi-vesicular bodies in the cytoplasm of frozen oocytes (Nottola et al., 2007; Nottola et al., 2009). We showed MSER aggregates decreasing in both frozen groups compared to the control and VIVM groups. Nottola et al. (2014), reported the reducing M-SER in IVM group compared to the control group in their study. Their results were similar to our results. Some observed changes in the architecture of in vitro matured oocytes such as reducing the cortical granules and M-SER aggregates may be associated with culture time and medium conditions (Nottola et al., 2014). In a study by Sprícigo et al., the morphology, molecular and functional 
patterns of bovine vitrified oocyte were evaluated at different times during in vitro maturation. They expressed that with prolongation of culture time, mitochondrial degeneration rate increased and cortical granules decreased (Sprícigo et al.). The findings of present study were similar to these results. In other studies, changes in the number of mitochondria and their distribution also were observed (Nazmara et al.). It was suggested that ultrastructural changes of M-SER aggregates in vitrified oocytes is probably related to the use of ethylene glycol in vitrification solutions to damages from the cooling. This material may lead to impaired calcium homeostasis and reduction in fertilization rate (Nottola et al., 2009).

M-SER aggregates are considered as a precursor complex of mitochondria and endoplasmic reticulum vesicles. As well, mitochondria and associated cytoplasmic membranes may be involved to produce materials which are necessary for fertilization or quick formation of new membranes in the early stages of embryogenesis M-SER aggregates (Motta et al., 2002) also may have essential role in the regulation of free calcium concentrations and ATP production. In this study, reducing of M-SER aggregates was observed in both fresh and frozen groups possibly related to the long time culture period. This can confirm the potential reduction of oocyte competence for fertilization because of disruption of calcium homeostasis (Nottola et al., 2009).

As a result of this study, immature oocytes should be matured first and then undergo vitrification in ART cycles. Vitrification may be associated with ultrastructural alterations in certain regions of the oocytes which probably responsible for the reduction of oocyte maturation. These findings emphasize on further studies to correct the freezing techniques.

IZADI, M.; EFTEKHAR, V. S. H.; AKBARI, H.; ASADI, S. M. \& MOKHTARI, T. Evaluación de la ultraestructura de los ovocitos de ratón después de la vitrificación antes y después de la maduración in vitro. Int. J. Morphol., 36(1):180-188, 2018.

RESUMEN: La vitrificación es un proceso físico en el que la solución concentrada de crioprotectores, después de la exposición al frío extremo sin formación de cristales de hielo en las células vivas, se convierte en estado de cristal. En este estudio, se evaluaron la velocidad de maduración y la ultraestructura de los ovocitos de ratón seguidos por la vitrificación antes o después de la maduración in vitro (IVM). Se obtuvieron un total de 373 ovocitos, de vesículas germinales de ovarios, y se dividieron en tres grupos de IVM vitrificados, IVM e IVM frescos. Diez ovocitos metafase II se obtuvieron a partir de tubas uterinas y se consideraron como el grupo de control. Los ovocitos en grupos vitrificados fueron vitrificados por Cryotop usando medio de vitrificación y mantenidos en nitrógeno líquido. El medio de maduración fue aMEM suplementado con rFSH + hCG. Después de 24-48 h de incubación, fueron observados en los ovocitos la maduración nuclear y cambios ultraestructurales utilizando microscopía electrónica de transmisión (MET). La tasa de maduración de los ovocitos en el grupo vIVM fue significativamente más baja que en el grupo IVMv, cuando los dos grupos se compararon con los que tenían la mayor madurez. La evaluación de la ultraestructura de los cuatro grupos mostró que el número de gránulos corticales, microvellosidades y acúmulos de mitocondrias-SER en el grupo vIVM fue el más bajo y el más alto entre el número de vacuolas. La zona pelúcida fue más oscura en dos grupos de congelación vIVM e IVMv, que en el grupo control. La mayoría de los grupos, similares al grupo de control, fueron los grupos vIVM, IVMv y, finalmente, el grupo vIVM, respectivamente. De acuerdo con los resultados, el procedimiento de IVM es más eficiente cuando se realiza antes de la vitrificación de ovocitos.

PALABRAS CLAVE: Vitrificación; Preservación fertilidad; Criopreservación; Maduración in vitro; Ultraestructura.

\section{REFERENCES}

Abedpour, N. \& Rajaei, F. Vitrification by cryotop and the maturation, fertilization, and developmental rates of mouse oocytes. Iran. Red Crescent Med. J., 17(10):e18172, 2015.

Ben-Ami, I.; Komsky, A.; Bern, O.; Kasterstein, E.; Komarovsky, D. \& Ron-El, R. In vitro maturation of human germinal vesicle-stage oocytes: role of epidermal growth factor-like growth factors in the culture medium. Hum. Reprod., 26(1):76-81, 2011.

Bonduelle, M.; Camus, M.; De Vos, A.; Staessen, C.; Tournaye, H.; Van Assche, E.; Verheyen, G.; Devroey, P.; Liebaers, I. \& Van Steirteghem, A. Seven years of intracytoplasmic sperm injection and follow-up of 1987 subsequent children. Hum. Reprod., 14 Suppl. 1:243-64, 1999.

Campos-Chillòn, L. F.; Suh, T. K.; Barcelo-Fimbres, M.; Seidel, G. E. Jr. \& Carnevale, E. M. Vitrification of early-stage bovine and equine embryos. Theriogenology, 71(2):349-54, 2009.

Cao, Y.; Xing, Q.; Zhang, Z. G.; Wei, Z. L.; Zhou, P. \& Cong, L. Cryopreservation of immature and in-vitro matured human oocytes by vitrification. Reprod. Biomed. Online, 19(3):369-73, 2009.

Chen, C. Pregnancy after human oocyte cryopreservation. Lancet, 1(8486):884-6, 1986.

Cobo, A.; Kuwayama, M.; Pérez, S.; Ruiz, A.; Pellicer, A. \& Remohí, J. Comparison of concomitant outcome achieved with fresh and cryopreserved donor oocytes vitrified by the Cryotop method. Fertil. Steril., 89(6):1657-64, 2008.

Combelles, C.; Cekleniak, N. A.; Racowsky, C. \& Albertini, D. F. Assessment of nuclear and cytoplasmic maturation in in-vitro matured human oocytes. Hum. Reprod., 17(4):1006-16, 2002.

Cooper, A.; Paynter, S. J.; Fuller, B. J. \& Shaw, R. W. Differential effects of cryopreservation on nuclear or cytoplasmic maturation in vitro in immature mouse oocytes from stimulated ovaries. Hum. Reprod., 13(4):971-8, 1998.

De Vos, A.; Van de Velde, H.; Joris, H. \& Van Steirteghem, A. In-vitro matured metaphase-I oocytes have a lower fertilization rate but similar embryo quality as mature metaphase-II oocytes after intracytoplasmic sperm injection. Hum. Reprod., 14(7):1859-63, 1999.

Elizur, S. E.; Chian, R. C.; Pineau, C. A.; Son, W. Y.; Holzer, H. E.; Huang, J. Y.; Gidoni, Y.; Levin, D.; Demirtas, E. \& Tan, S. L. Fertility preservation treatment for young women with autoimmune diseases facing treatment with gonadotoxic agents. Rheumatology (Oxford), 
47(10):1506-9, 2008.

Fasano, G.; Demeestere, I. \& Englert, Y. In-vitro maturation of human oocytes: before or after vitrification? J. Assist. Reprod. Genet., 29(6):507-12, 2012.

Fasano, G.; Vannin, A. S.; Biramane, J.; Delbaere, A. \& Englert, Y. Cryopreservation of human failed maturation oocytes shows that vitrification gives superior outcomes to slow cooling. Cryobiology, 61(3):243-7, 2010.

Flaws, J. A.; Hirshfield, A. N.; Hewitt, J. A.; Babus, J. K. \& Furth, P. A. Effect of bcl-2 on the primordial follicle endowment in the mouse ovary. Biol. Reprod., 64(4):1153-9, 2001.

Fuku, E.; Xia, L. \& Downey, B. R. Ultrastructural changes in bovine oocytes cryopreserved by vitrification. Cryobiology, 32(2):139-56, 1995.

Gardner, D. K.; Sheehan, C. B.; Rienzi, L.; Katz-Jaffe, M. \& Larman, M. G. Analysis of oocyte physiology to improve cryopreservation procedures. Theriogenology, 67(1):64-72, 2007.

Ghetler, Y.; Skutelsky, E.; Ben Nun, I.; Ben Dor, L.; Amihai, D. \& Shalgi,s R. Human oocyte cryopreservation and the fate of cortical granules. Fertil. Steril., 86(1):210-6, 2006.

Gook, D. A. \& Edgar, D. H. Human oocyte cryopreservation. Hum. Reprod. Update., 13(6):591-605, 2007.

Homburg, R.; van der Veen, F. \& Silber, S. J. Oocyte vitrification--women's emancipation set in stone. Fertil. Steril., 91(4 Suppl.):1319-20, 2009.

Hreinsson, J. \& Fridström, M. In vitro oocyte maturation for safer treatment of infertility. The risk of ovarian overstimulation syndrome is minimized. Lakartidningen, 101(46):3665-8, 2004.

Huang, J. Y.; Chen, H. Y.; Park, J. Y.; Tan, S. L. \& Chian, R. C. Comparison of spindle and chromosome configuration in in vitro- and in vivo-matured mouse oocytes after vitrification. Fertil. Steril., 90(4 Suppl.):1424-32, 2008.

Kennedy, J. F. \& Donahue, R. P. Human ooeytes: Maturation in chemically defined media. Science, 164(3885):1292-3, 1969.

Motta, P. M.; Nottola, S. A.; Familiari, G.; Makabe, S.; Stallone, T. \& Macchiarelli, G. Morphodynamics of the follicular-luteal complex during early ovarian development and reproductive life. Int. Rev. Cytol., 223:177288,2002

Nazmara, Z.; Salehnia, M. \& HosseinKhani, S. Mitochondrial distribution and ATP content of vitrified, in vitro matured mouse oocytes. Avicenna J. Med. Biotechnol., 6(4):210-7, 2014.

Nottola, S. A.; Coticchio, G.; Khalili, M. A.; Miglietta, S.; Palmerini, M. G. \& Macchiarelli, G. Ultrastructure of human in vitro-matured (IVM) oocytes. Ital. J. Anat. Embryol., 119(1 Suppl.):143, 2014.

Nottola, S. A.; Coticchio, G.; Sciajno, R.; Gambardella, A.; Maione, M.; Scaravelli, G.; Bianchi, S.; Macchiarelli, G. \& Borini, A. Ultrastructural markers of quality in human mature oocytes vitrified using cryoleaf and cryoloop. Reprod. Biomed. Online, 19 Suppl. 3:17-27, 2009.

Nottola, S. A.; Macchiarelli, G.; Coticchio, G.; Bianchi, S.; Cecconi, S.; De Santis, L.; Scaravelli, G.; Flamigni, C. \& Borini, A. Ultrastructure of human mature oocytes after slow cooling cryopreservation using different sucrose concentrations. Hum. Reprod., 22(4):1123-33, 2007.

Oryan Abkenar, Z.; Ganji, R.; Eghbal Khajehrahimi, A. \& Bahadori, M. H. Vitrification and subsequent in vitro maturation of mouse preantral follicles in presence of growth factors. Cell J., 16(3):271-8, 2014.

Paynter, S. J. Current status of the cryopreservation of human unfertilized oocytes. Hum. Reprod. Update, 6(5):449-56, 2000.

Shahedi, A.; Hosseini, A.; Khalili, M. A.; Norouzian, M.; Salehi, M.; Piriaei, A. \& Nottola, S. A. The effect of vitrification on ultrastructure of human in vitro matured germinal vesicle oocytes. Eur. J. Obstet. Gynecol. Reprod. Biol., 167(1):69-75, 2013.

Shi, L. Y.; Jin, H. F.; Kim, J. G.; Mohana Kumar, B.; Balasubramanian, S.; \& Choe, S. Y. \& Rho, G. J. Ultra-structural changes and developmental potential of porcine oocytes following vitrification. Anim. Reprod. Sci., 100(1-2):128-40, 2007.

Son, W. Y.; Park, S. E.; Lee, K. A.; Lee, W. S.; Ko, J. J.; Yoon, T. K. \& Cha, K. Y. Effects of 1,2-propanediol and freezing-thawing on the in vitro developmental capacity of human immature oocytes. Fertil. Steril., 66(6):995-9, 1996.
Sprícigo, J. F.; Morais, K.; Ferreira, A. R.; Machado, G. M.; Gomes, A. C.; Rumpf, R.; Franco, M. M. \& Dode, M. A. Vitrification of bovine oocytes at different meiotic stages using the Cryotop method: assessment of morphological, molecular and functional patterns. Cryobiology, 69(2):256-65, 2014

Toth, T. L.; Baka, S. G.; Veeck, L. L.; Jones, H. W. Jr.; Muasher, S. \& Lanzendorf, S. E. Fertilization and in vitro development of cryopreserved human prophase I oocytes. Fertil. Steril., 61(5):891-4, 1994.

Tucker, M. J.; Morton, P. C.; Wright, G.; Sweitzer, C. L. \& Massey, J. B. Clinical application of human egg cryopreservation. Hum. Reprod., 13(11):3156-9, 1998

Valojerdi, M. R. \& Salehnia, M. Developmental potential and ultrastructural injuries of metaphase II (MII) mouse oocytes after slow freezing or vitrification. J. Assist. Reprod. Genet., 22(3):119-27, 2005.

Van Blerkom, J. Maturation at high frequency of germinal-vesicle-stage mouse oocytes after cryopreservation: alterations in cytoplasmic, nuclear, nucleolar and chromosomal structure and organization associated with vitrification. Hum. Reprod., 4(8):883-98, 1989.

van Uem, J. F.; Siebzehnrübl, E. R.; Schuh, B.; Koch, R.; Trotnow, S. \& Lang, N. Birth after cryopreservation of unfertilized oocytes. Lancet, 1(8535):752-3, 1987.

Walschaerts, M.; Bujan, L.; Isus, F.; Parinaud, J.; Mieusset, R. \& Thonneau, P. Cumulative parenthood rates in 1735 couples: impact of male factor infertility. Hum. Reprod., 27(4):1184-90, 2012.

Wu, C.; Rui, R.; Dai, J.; Zhang, C.; Ju, S.; Xie, B.; Lu, X. \& Zheng, X. Effects of cryopreservation on the developmental competence, ultrastructure and cytoskeletal structure of porcine oocytes. Mol. Reprod. Dev., 73(11):1454-62, 2006.

Wu, J.; Zhang, L. \& Wang, X. In vitro maturation, fertilization and embryo development after ultrarapid freezing of immature human oocytes. Reproduction, 121(3):389-93, 2001.

Yoon, T. K.; Kim, T. J.; Park, S. E.; Hong, S. W.; Ko, J. J.; Chung, H. M. \& Cha, K. Y. Live births after vitrification of oocytes in a stimulated in vitro fertilization-embryo transfer program. Fertil. Steril., 79(6):13236, 2003.

\section{Corresponding author \\ Seyed Hassan Eftekhar Vaghefi, PhD \\ Department of Anatomical Sciences \\ Afzalipour School of Medicine \\ Kerman University of Medical Sciences \\ Kerman \\ IRAN}

Email: mn.sam2000@gmail.com

Received:10-08-2017

Accepted: 20-10-2017 